\title{
Outflow Reconstruction Techniques in Living Donor Liver Transplantation
}

\author{
Ender Dulundu
}

\author{
*Corresponding author: \\ Ender Dulundu, MD, FACS \\ Professor of Surgery, \\ HPB Surgery \& Head of Liver \\ Transplantation Unit \\ Marmara University, School of \\ Medicine, Istanbul, Turkey \\ Ph: +90 5333856561 \\ e-mail: edulundu@dr.com
}

\section{Abbreviations:}

LDLT: living donor liver transplantation; IVC: inferior vena cava; MHV: middle hepatic vein; IRHV: inferior right hepatic vein; LHV - left hepatik vein; GSV - great saphenous vein; PTFE - polytetrafluoroethylene.

\author{
HPB Surgery, Liver Transplantation Unit, Marmara University, School of Medicine \\ Istanbul, Turkey
}

\section{ABSTRACT}

Liver transplantation is a therapeutic option for acute and chronic end stage liver diseases and certain hepatic malignant tumors. The growing disparity between the number of liver transplant candidates and the supply of deceased donor organs has led the increase living donor liver transplantation (LDLT). The provision of an adequate outflow is indispensable for graft function. In order to meet the metabolic demand of the recipient, the majority of the transplant centers switched to a right lobe from the left lobe LDLT which makes hepatic venous reconstruction more complicated. Additionally, the regenerative process of the hepatic allograft may lead dynamic changes in the spatial orientation of reconstructed blood vessels, especially the hepatic venous outflow. Different technical approaches and algorithms have been developed to prevent graft congestion and to perform a sufficient outflow reconstruction. In this review, several considerations of outflow reconstruction techniques are discussed on the basis of our experience and the literature.

Key words: outflow, living donor liver transplantation, outflow reconstruction technique, vascular graft

\section{INTRODUCTION}

Liver transplantation is a therapeutic option for acute and chronic end stage liver diseases and certain hepatic malignant tumors. In western country, while the majority of liver transplantation is deceased-donor liver transplantation, this is not a case in Asian Countries, and living donor liver transplantation (LDLT) constitute the majority of the cases. The patency of hepatic venous outflow is important to graft survival, and one of the major prerequisites for technically successful LDLT is good outflow (1-5).

Outflow occlusion and congestion lead to suboptimal graft function, graft failure and, even patient death because of the small for size graft syndrome (6). Reported incidences of hepatic venous outflow obstruction after LDLT is between $1.5 \%$ to $16.6 \%$ in the literature $(2,6,7,8)$.

Commonly reported causes of hepatic venous outflow obstruction include tight suture line, twisting of the anastomosis due to inappropriate graft positioning or regeneration, size discrepancy between native venous orifice and graft hepatic vein opening, and peri-anastomotic fibrosis secondary to inflammation (9). 
In early cases in a standard technique an end-to-side anastomosis has been using. Inferior vena cava (IVC) is cross clamped at suprahepatic and infra-hepatic region. A triangular slit is created on the anterior wall of the IVC, and the hepatic venous branches, which were joined on the back table, are anastomosed end-to-side to the caval window $(1,2,10)$.

However, a direct anastomosis of the hepatic veins to the IVC can cause bend in the IVC at the anastomotic side, which can result in outflow occlusion (11).

Additionally, in the presence of the thick short hepatic veins, caudate veins or IRHVs additional IVC anastomosis have to be done by creating a separate venotomy on the IVC and this can technically complicate the operation. Graft regeneration can lead to hepatic vein stenosis and graft congestion, especially when the ouflow tract is narrow and the distance from IVC is short $(8,11,12)$.

It is well known that not only the actual graft volume but also the uncongested graft volume is a very important for the successful LDLT. Therefore, the congested area of the graft should be minimized as much as possible; thus, it is necessary to obtain a wide ostium and a sufficient length of the hepatic vein for anasto- mosis (12). And, become important to reconstruction the venous tributaries of caudate vein, middle hepatic vein (MHV), inferior right hepatic vein (IRHV), and thick short hepatic veins (> $5 \mathrm{~mm}$ ). However direct anastomosis of this vessels to the inferior vena cava (IVC) is technically difficult and prolongs warm ischemia time. In this sense to overcome these problems vascular graft such an autologous (ie.great saphenous vein, portal vein, umbilical vein, hepatic vein), cryopreserved vascular graft, and synthetic vascular grafts can be used $(4,13,14,15)$.

\section{LEFT LIVER}

Many groups spend efforts to using left liver graft in order to not to compromising safety of the donor (16). In practice, full left lobe grafts include Couinaud segments 2, 3, and 4 with the MHV. Left hepatik vein (LHV) and MHV in the recipient can be joined into one. If the diameter of the joined veins is smaller than the left liver graft's hepatic vein, a wider orifice can be constructed by venoplasty of three hepatic veins in the recipient (17). Where the joined MHV and LHV is not enough in width and size vascular graft can be used to enlarged it. Figure 1 showing left LDLT using an
Figure 1 - Left LDLT using an umbilical vein of the recipient as vascular graft

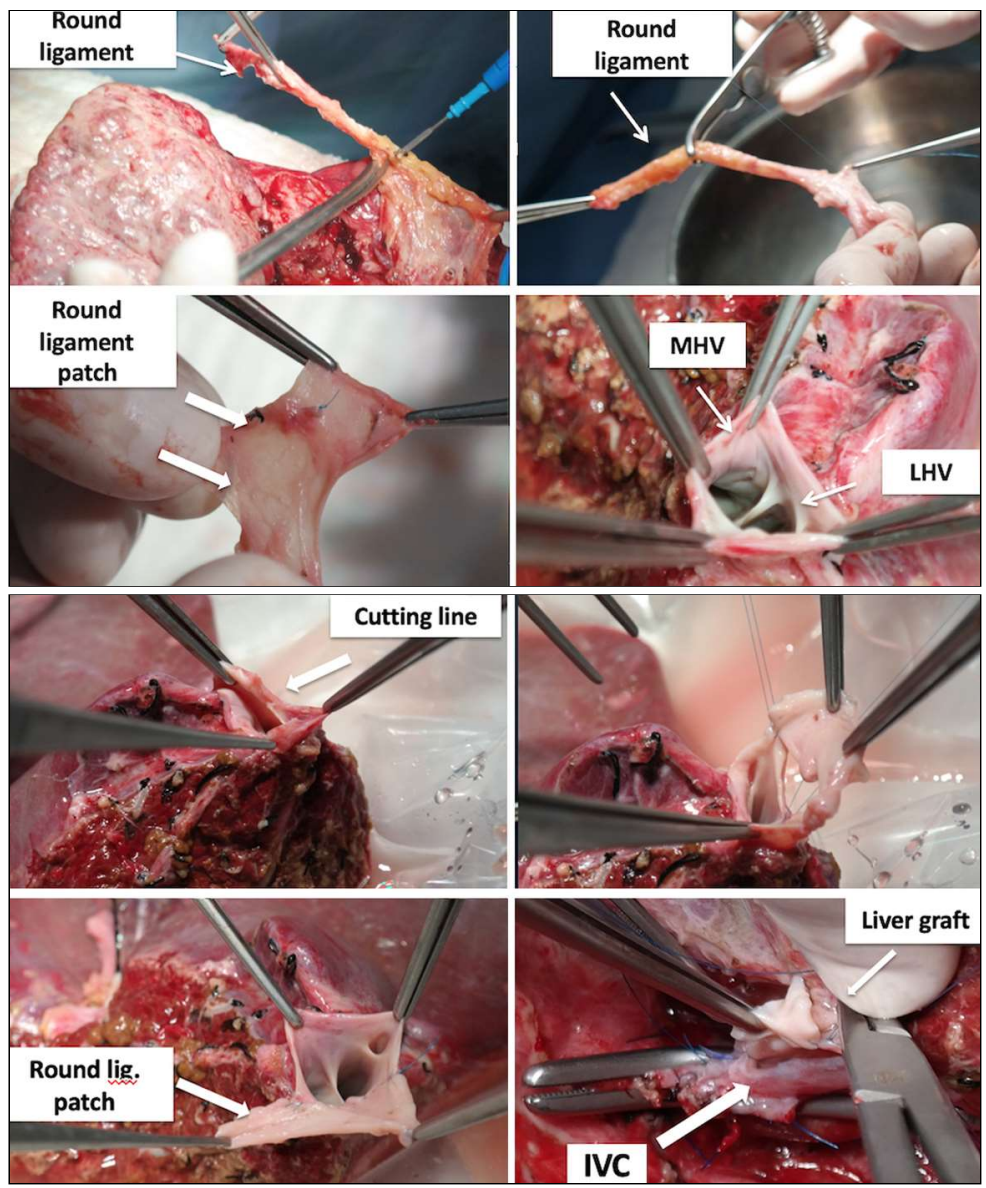


Figure 2 - Left LDLT using a great saphenous for reconstruction of the hepatic veins
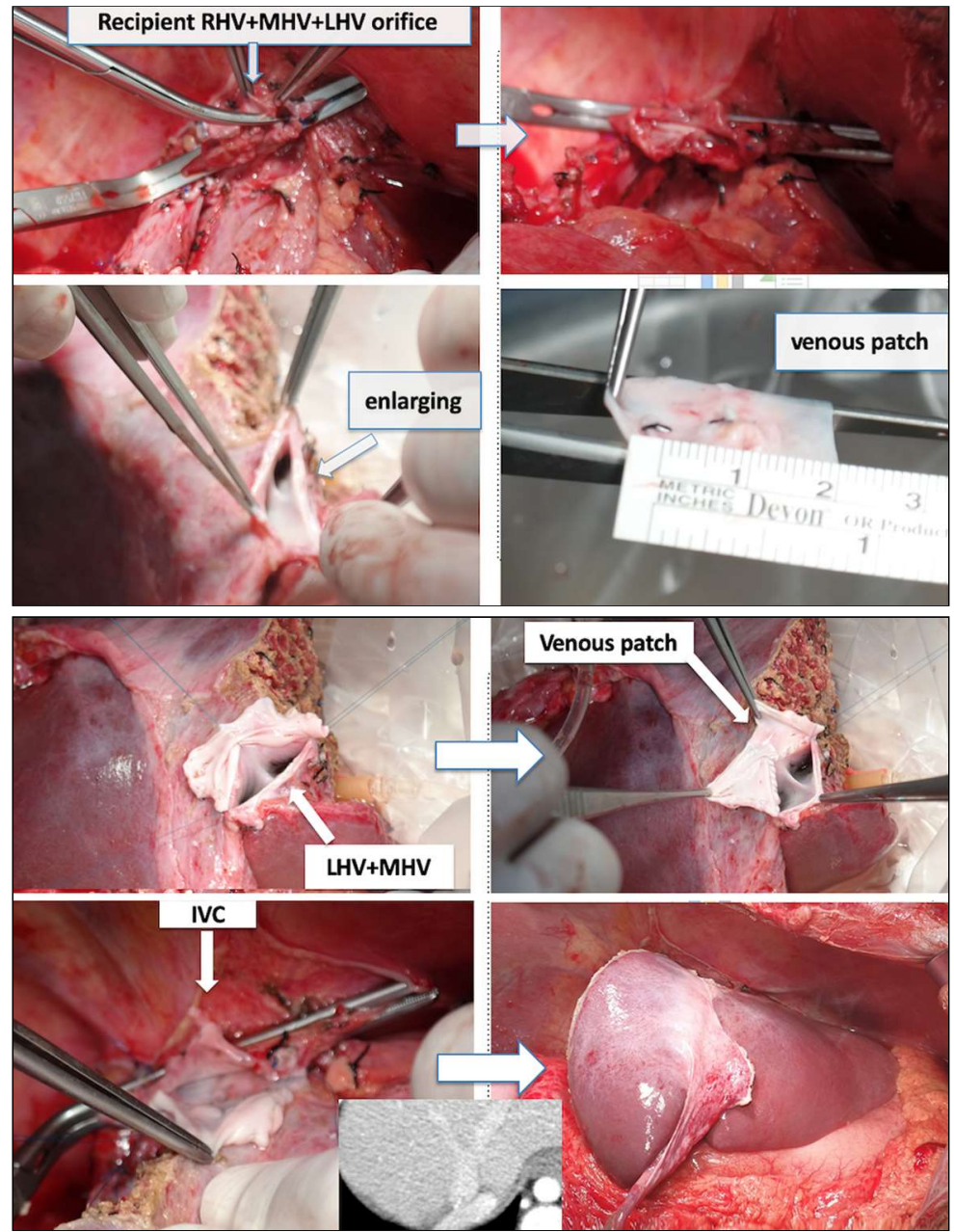

umbilical vein of the recipient (fig. 2) showing a left LDLT using a great saphenous vein (GSV).

\section{LEFT LIVER WITH CAUDATE LOBE}

To overcome small-for-size graft problem Miyagawa proposed the use of the left caudate lobe with a left liver graft, and with this procedure graft liver volume increased by $8-12 \%$ (18).

Cast studies has shown that $91 \%$ of the caudate vein entered directly to the vena cava (19).

Takayama and colleagues emphasized the importance of short hepatic reconstruction to prevent venous congestion of the caudate lobe (20).

The hepatic vein of the caudate lobe can be resected with a cuff of the vena cava, which resembles a Carrel's patch and directly anastomosed to the recipient's vena cava. Figure 3 showing the preparation of caudate lobe with a carrel patch.

When the orifice of the short hepatic vein is located near those of the LHV and MHV, the caudate vein with a cuff of inferior vena cava can be sutured to the common orifice of the LHV and MHV (21). When the caudate vein is distant from the common orifice of LHV and $\mathrm{MHV}$, vascular graft can be placed between them to make a unique and wide anastomosis.

Figure 4 showing left LDLT with caudate lobe using a GSV as a vascular graft for reconstruction, fig. 5 showing left LDLT with caudate lobe using a cryopreserved vena cava as a vascular graft for reconstruction.

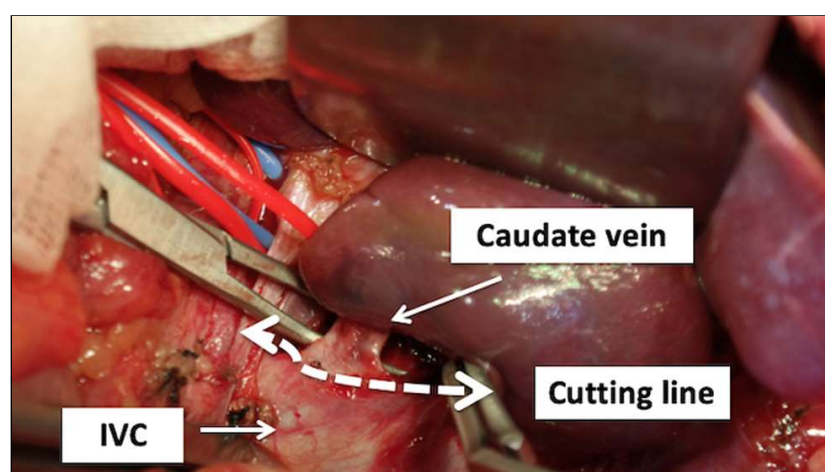

Figure 3 - showing the preparation of caudate lobe with a carre patch 
Figure 4 - showing left LDLT with caudate lobe using a GSV as a vascular graft for reconstruction
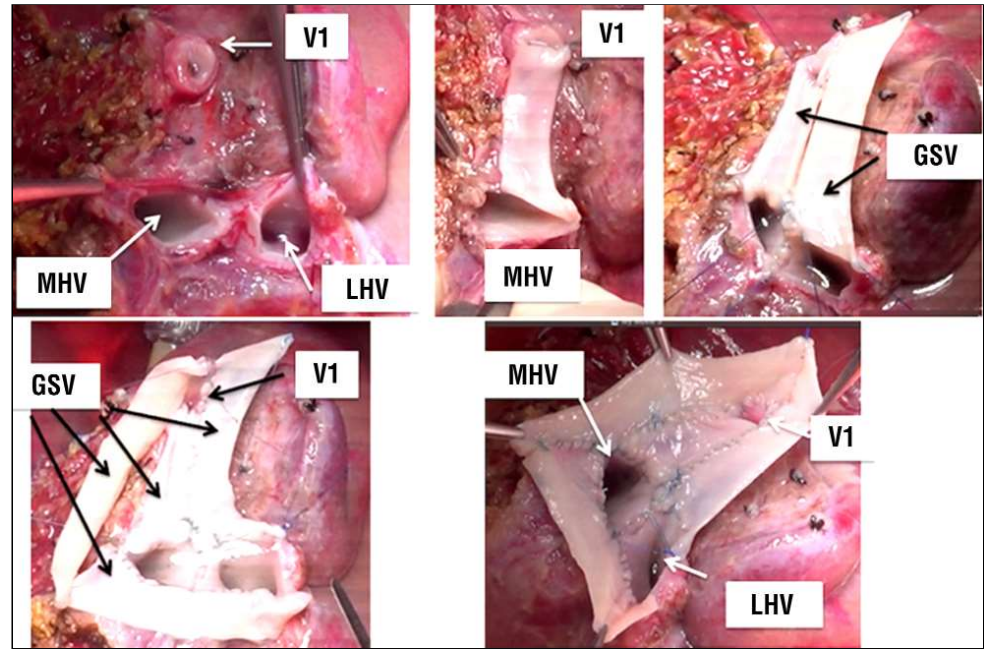

\section{RIGHT LIVER}

To overcome small-for-size problem Lo and colleagues performed first LDLT using extended right lobe graft, which includes Couinaud's segments 5, 6, 7 , and 8 with the MHV (22). With this method the graft is quite large and decrease the rate of liver disfunction in recipient caused by small-for-size syndrome. However, in the donor, draining area by the MHV of the segment IV will be congested, and may lead liver dysfunction in the donor (23).

To mitigate this higher donor risk, some groups limited the right lobe allograft to not include the middle hepatic vein. On the other hand, a right liver graft without the trunk of the MHV can cause severe congestion of the segment 5 , and 8 without MHV reconstruction. The importance of venous outflow reconstruction during this early experience, prompted separate implantation of any short hepatic vein larger than $5 \mathrm{~mm}$ in diameter, and recently the international
Liver Transplantation Society recommends the same principle $(24,25)$.

The development of the collateral circulation that drains the ligated MHV tributaries may occur in approximately 1 week (26). Nakamura et al. has shown that the congestive area resulted in histologic necrosis of the hepatic parenchyma approximately 24 hours after the ligation, even in the patients who developed intrahepatic venous collaterals draining the congestive area after 7 days (27).

Venous congestion of the right anterior sector (segment 5 and 8) after transplantation may lead to early postoperative venous congestion that may cause graft dysfunction, prolonged jaundice and ascites that mimicked small-for-size syndrome (6). Therefore, Kinkhabwala $M$. et al reported that V5 and V8 reconstruction could be reserved for grafts of marginal size or quality (3). It was reported that MHV had proper branches draining the anterior section in $26.5 \%$ of cases (28).
Figure 5 - showing left LDLT with caudate lobe using a cryopreserved vena cava as a vascular graft for reconstruction

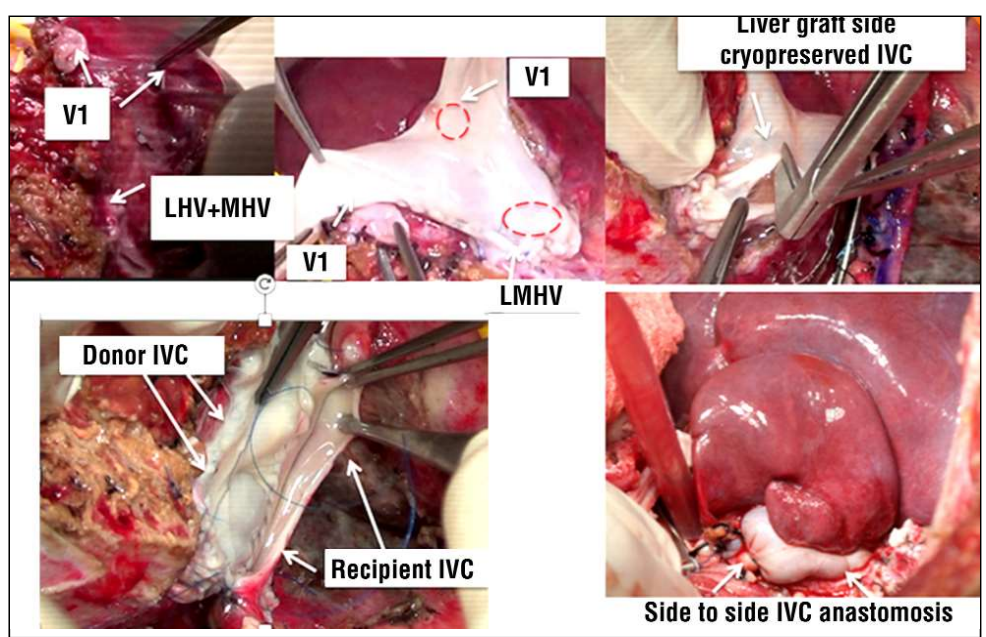


Figure 6 - Right liver graft with IRHV, 2 V5 and 1 V8 reconstruction using a great saphenous vein
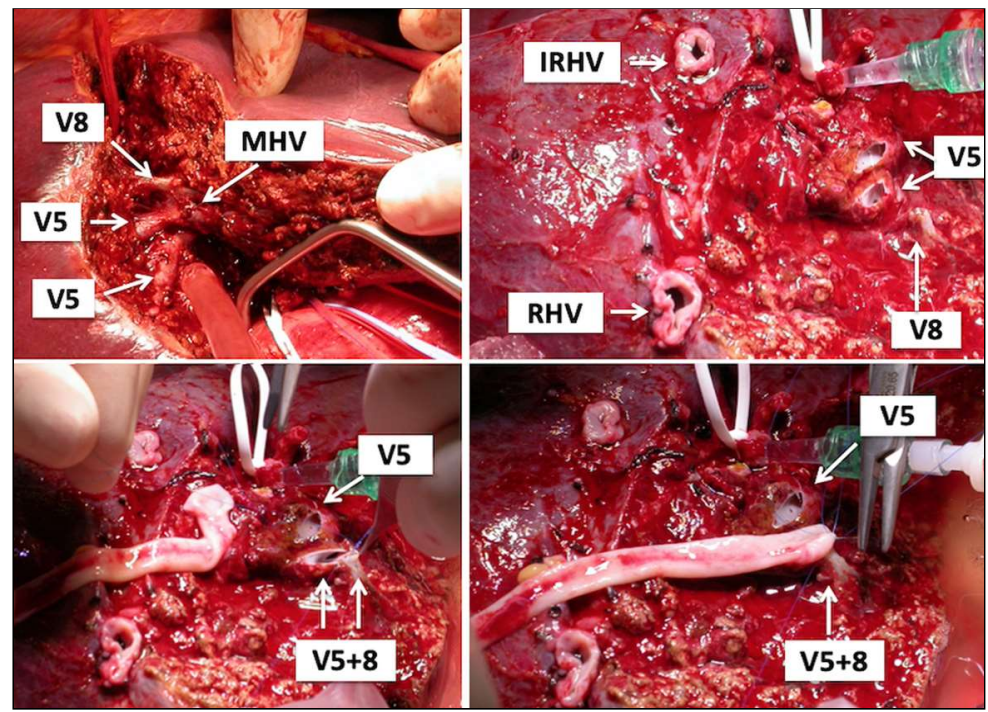

The policy of Kyoto group is to reconstruct V5 or V8 in right liver graft if each congestion area of drainage vein exceeds $10 \%$ of the liver graft (29).

According to Tokyo University policy first, discoloration of the liver surface is observed after concomitant clamping of the MHV tributary and relevant artery for 5 minutes. Thereafter, only the hepatic artery is declamped and Doppler ultrasonography is performed. When hepatofugal portal flow is observed, the relevant area of the liver is confirmed to be congested. If the liver volume, excluding the area discolored by occlusion of the artery, if estimated graft volume less than $40 \%$ of the recipient's standard liver volume, the MHV tributaries are reconstructed. Some criteria are used for the thick short hepatic veins (i.e.' inferior right hepatic vein, middle right hepatic vein) $(12,30,31)$.

These veins can be reconstructed using inter- position grafts from recipient's autologous native vein (ie. portal vein, umbilical vein, great saphenous vein), cryopreserved veins, or synthetic vascular grafts (ie.polytetrafluoroethylene vascular grafts) $(4,29,32,33,34,35)$. Each of these patency rates is excellent, and there is no evidence that any method is superior (fig. 6, 7, 8).

Cryopreserved vascular grafts can liberally be used for outflow vascular reconstruction. They have some advantages over to synthetic grafts; they are resistant to infection, biocompatible and superior flexibility, require no anticoagulation, various shape and size available, storable, they have no donor site morbidity, and not time-consuming contrary reduced the warm ischemia time especially in complex cases $(4,14,36-38)$. Additionally to all those, cryopreserved vascular grafts make the operation possible in a special cases such a patients with an IVC agenesia (40).
Figure 7 - Right liver graft with IRHV, 2 V5 and 1 V8 after reconstruction using a great saphenous vein
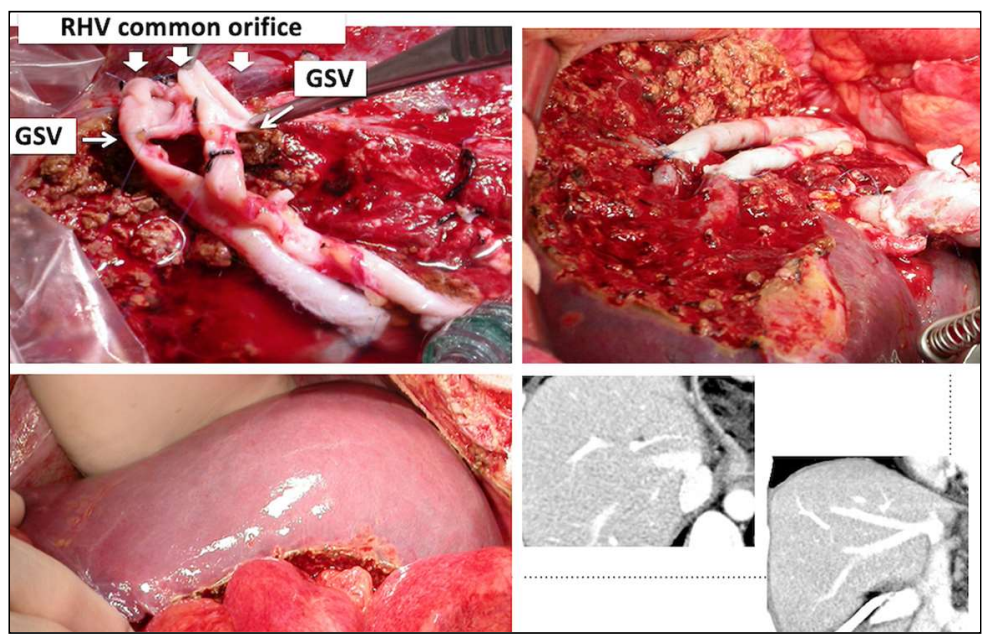
Figure 8 - Right liver graft with V5 and V8 reconstructing using a synthetic vascular graft

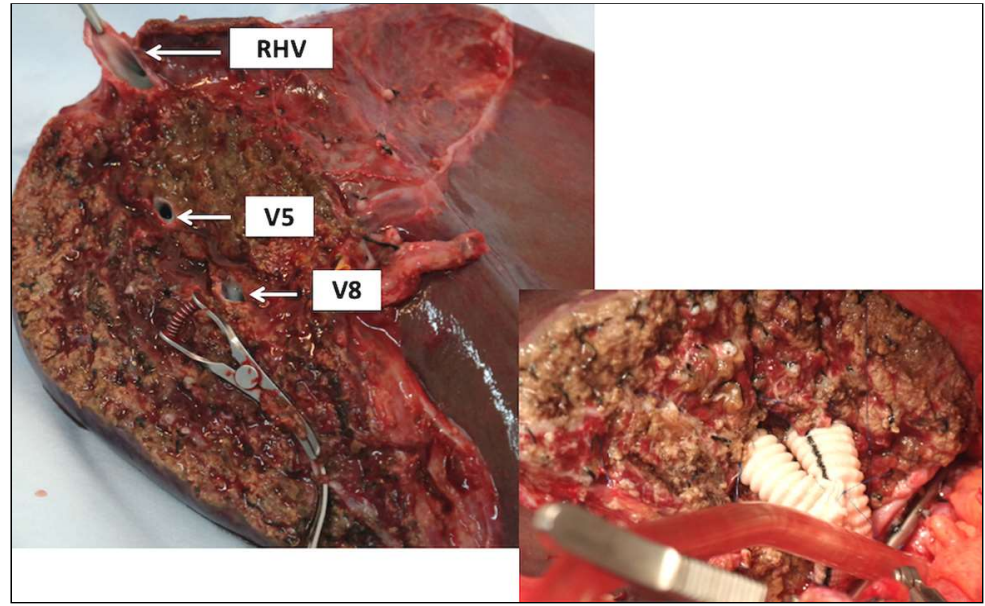

\section{IVC RESECTION AND RECONSTRUCTION USING SYNTHETIC GRAFT}

Some patients have a severe dense adhesions and inflammation between the diseased liver and IVC in such instances total hepatectomy is not possible without resection of the IVC. Reconstruction can be done by synthetic graft, and although graft infection and thrombosis are major concerns, liver graft implanted to reconstructed IVC (39) (fig. 9).

Synthetic graft liberally use in some centers; polytetrafluoroethylene (PTFE) grafts without external rings are vulnerable to buckling and even shrinkage by external compression of a distended stomach, perigraft hematoma or fluid collection, but ringed PTFE grafts appear more resistant to those environments (5). PTFE grafts can induce a severe inflammatory reaction at the anastomotic site, resulting in early lumen narrowing (33). It must be careful when use PTFE grafts in contaminated environments (i.e. bile leak) may rise from its increased vulnerability to bacterial colonization (5).

\section{CONCLUSION}

Graft congestion that may lead to graft dysfunction an even early graft failure, especially in marginally sized donor grafts.

Outflow tract reconstruction is critical for proper graft functioning in LDLT. To ensure that innovative venoplasty techniques using cryopreserved vascular graft, aouto vascular graft and even synthetic graft like PTFE can be used. Although it takes time on the back table, they facilitates the implantation of the graft during the surgery.

\section{Conflict of interest}

The author have neither conflicts of interest nor source of funding to disclose.
Figure 9 - Left LDLT using synthetic vascular graft for IVC and homologues graft for the hepatic veins
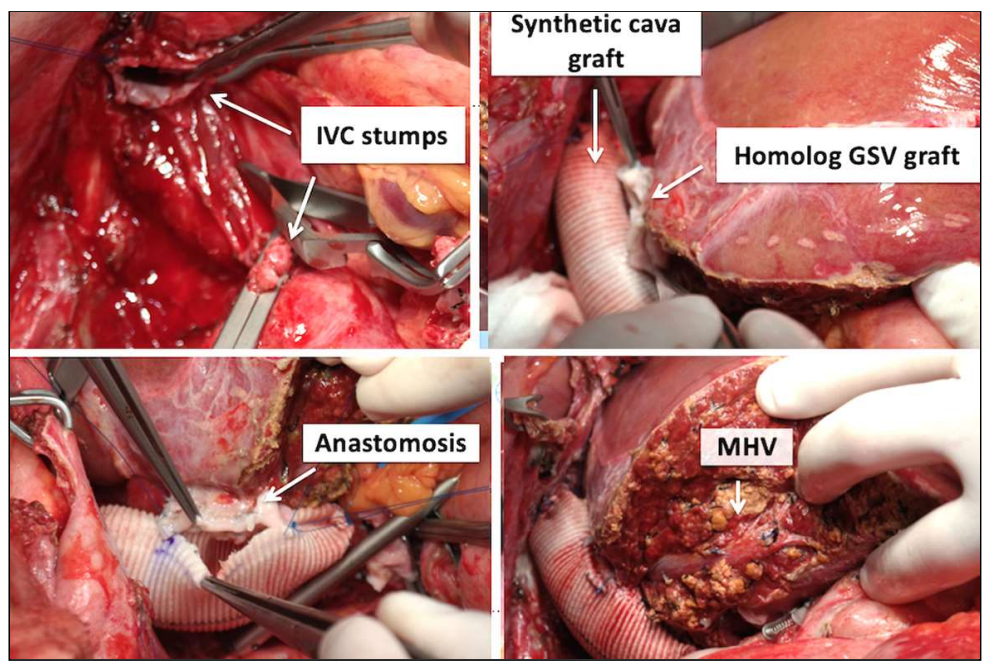


\section{REFERENCES}

1. Emond J, Heffron T, Whitington P, Broelsch C. Reconstruction of the hepatic vein in reduced size hepatic transplantation. Surg Gyneco Obstet. 1993;176:11-7.

2. Egawa H, Inomata Y, Uemoto S, K Asonuma, T Kiuchi, Okajima H, et al. Hepatic vein reconstruction in 152 living-related donor liver transplantation patients. Surgery. 1997:121(3):250-7.

3. Kinkhabwala MM, Guarrera JV, Leno R, Brown RS, Prowda J, Kapur $\mathrm{S}$, et al. Outflow reconstruction in right hepatic live donor liver transplantation. Surgery. 2003;133(3):243-50.

4. Sugawara Y, Makuuchi M, Akamatsu N, Kishi Y, Niiya T, Kaneko J, et al. Refinement of venous reconstruction using cryopreserved veins in right liver grafts. Liver Transpl. 2004;10(4):541-7.

5. Lee SG. A complete treatment of adult living donor liver transplantation: a review of surgical technique and current challengesto expand indication of patients. Am J Transplant 2015:15:17-38.

6. Lee S, Park K, Hwang S, Lee Y, Choi D, Kim K, et al. Congestion of right liver graft in living donor liver transplantation. Transplantation. 2001;71(6):812-4.

7. Someda $\mathrm{H}$, Moriyasu F, Fujimoto $M$, Hamato $N$, Nabeshima $M$, Nishikawa K, et al. Vascular complications in living related liver transplantation detectedwith intraoperative and postoperative Doppler US. J Hepatol. 1995;22(6):623-32

8. Kitajima T, Kaido T, lida T, Yagi S, Fujimoto Y, Ogawa K, et al. Left lobe graft poses a potential risk of hepatic venous outflow obstruction in adult living donor liver transplantation. Liver Transpl. 2016 22(6):785-95

9. Umehara M, Narumi S, Sugai M, Toyoki Y, Ishido K, Kudo D, et al. Hepatic venous outflowobstruction in living donor liver transplantation: balloon angioplasty or stent placement? Transplant Proc. 2012 44(3):769-71. doi: 10.1016/j.transproceed.2012.01.048.

10. Sugawara $Y$, Makuuchi M, Technical advances living-related liver transplantation. J Hepatobiliary Pancreat Surg. 1999:6(3):245-53.

11. Takayama T, Makuuchi M, Kawarasaki H, Kawasaki S, Matsunami H, Yasuhiko $\mathrm{H}$, et al. Venocavaplasty to overcome outflow block in living related liver transplantation. Transplantation. 1994;58(1):116-8.

12. Dulundu E, Sugawara Y, Makuuchi M. Revolution and refinement of surgical techniques for living donor partial liver transplantation. Yonsei Med J. 2004;45(6):1076-88.

13. Chia-Cheng Lin, Chia-En Hsieh, Yao-Li Chen. Great saphenous vein harvesting for venous outflow reconstruction in living donor liver transplantation-a minimally invasive refinement of the conventional procedure. Int J Surg. 2013;11(3):249-52.

14. Sugawara Y, Makuuchi M, Imamura H, Kaneko J, Kokudo N. Outflow reconstruction in extended right liver grafts from living donors. Liver Transpl. 2003;9(3):306-9.

15. Hashimoto T, Sugawara Y, Tamura S, Junichi Kaneko, Noboru Motomura, Shinichi Takamoto, et al. One orifice vein reconstruction in left liver plus caudate lobe grafts. Transplantation. 2007;83(2): 225-7.

16. Kawaguchi Y, Hasegawa K, Okura N, Maki H, Akamatsu N, Kaneko J et al. Influence of outflow-obstructed liver volume and venous communication development:A three-dimensional volume study in living donors. Liver Transpl. 2017;23(12):1531-1540.

17. Makuuchi M, Sugawara Y. Living-donor liver trasnplantation using left liver, with special reference to vein reconstruction. Transplantation. 2003;75(3 Suppl):S23-4.

18. Miyagawa S, Hashikura Y, Miwa S, Ikegami T, Urata K, Terada M, et al. Concomitant caudate lobe resection as an option for donor hepatectomy in adult living related liver transplantation. Transplantation. 1998;66(5):661-3.

19. Couinaud $\mathrm{C}$. The paracaval segments of the liver. J Hepatobiliary Pancreat Surg 1994;2:145.

20. Takayama T, Makuuchi M, Kubota K, Sano K, Harihara Y, Kawarasak H. Living-related transplantation of left liver plus caudate lobe. J Am Coll Surg. 2000;190(5):635-8.
21. Sugawara $Y$, Makuuchi M, Kaneko J, Ohkubo T, Matsui Y, Imamura $H$. New venoplasty technique for the left liver plus caudate lobe in living donor liver transplantation. Liver Transpl. 2002;8(1):76-7.

22. Lo CM, Fan ST, Liu CL, Lo RJ, Lau GK, Wei WI, et al. Extending the limit on the size of adult recipient in living donor liver transplantation using extended right lobe graft. Transplantation. 1997;63(10):1524-8.

23. Makuuchi M. Living donor liver transplantation:looking back at my 30 years. Surg Today. 2019;49(4):288-294.

24. Marcos A, Fisher RA, Ham JM, Shiffman ML, Sanyal AJ, Luketic VA, et al. Right lobe living donor liver transplantation. Transplantation 1999;68(6):798-803.

25. Miller CM, Quintini C, Dhawan A, Durand F, Heimbach JK, KimSchluger $\mathrm{HL}$, et al. The international liver transplantation society living donor liver transplant recipient guideline. Transplantation. 2017;101(5):938-944.

26. Tetsuya K, Kenichiro K, Hiroyuki S, Soichiro I, Tsuyoshi H, Kenro S, et al. Intrahepatic anastomosis formation between the hepatic veins in the graft liver of the living related liver transplantation: observation by doppler ultrasonography. Transplantation. 2000;70(6):982-5

27. Nakamura S, Sakaguchi S, Hachiya T, Suzuki S, Nishiyama R, Konno $\mathrm{H}$, et al. Significance of hepatic vein reconstruction in hepatectomy. Surgery 1993;114:59-64.

28. Nakamura S, Tsuzuki T. Surgical anatomy of the hepatic veins and the inferior vena cava. Surg Gynecol Obstet. 1981;152(1):43-50.

29. Shehata M, Yagi S, Ogura Y, Ogawa K, lida T, Mori A, et al. Use of recipient's left colic artery for arterial reconstruction during liver transplantation in Alagille syndrome with vasculopathy: a case report. Transplantation. 2012;93(6):e20-1.

30. Sano K, Makuuchi M, Takayama T, Sugawara Y, Imamura H, Kawarasaki $\mathrm{H}$. Technical dilemma in living-donor or split-liver transplant. Hepatogastroenterology. 2000;47(35):1208-9.

31. Sano K, Makuuchi M, Miki K, Maema A, Sugawara Y, Imamura H, et al. Evaluation of hepatic venous congestion: Proposed indication criteria for hepatic vein reconstruction. Ann Surg. 2002;236(2):241-7.

32. Gyu Lee S, Min Park K, Hwang S, Hun Kim K, Nak Choi D, Hyung Joo S, et al. Modified right liver graft from a living donor to prevent congestion. Transplantation. 2002;74(1):54-9.

33. Hwang S, Jung DH, Ha TY, Ahn CS, Moon DB, Kim KH, et al. Usability of ringed polytetrafluoroethylene grafts for middle hepatic vein reconstruction during living donor liver transplantation. Liver Transpl. 2012;18(8):955-65.

34. Jeng LB, Thorat A, Li PC, Li ML, Yang HR, Yeh CC, et al. "V-Plasty" technique using dual synthetic vascular grafts to reconstruct outflow channel in living donor liver transplantation. Surgery. 2015; 158(5): 1272-82.

35. Dayangac M, Tokat $Y$. The evolution sector venous drainage in right lobe living donor liver transplantation:does one technique fit all? Hepatobiliary Surg Nutr. 2016;5(2):151-158.

36. Takemura N, Sugawara $Y$, Hashimoto T, Akamatsu N, Kishi $Y$ Tamura S, et al. New hepatic vein reconstruction in left liver graft. Liver Transpl. 2005;11(3):356-60.

37. Kishi Y, Sugawara Y, Matsui Y, Akamatsu N, Motomura N, Takamoto $\mathrm{S}$, et al. Alternatives to the double vena cava method in partial liver transplantation. Liver Transpl. 2005;11(1):101-3.

38. Sugawara Y, Makuuchi M, Sano K, Imamura H, Kaneko J, Ohkubo T, et al. Vein reconstruction in modified right liver graft for living donor liver transplantation. Ann Surg. 2003;237(2):180-5.

39. Hsu SC, Jeng LB, Thorat A, Li PC, Poon KS, Hsu CH, et al. Management of extensive retrohepatic vena cava defect in recipients of living donor liver transplantation. Transplant Proc. 2014;46(3): 699-704.

40. Dulundu E, Sugawara Y, Kaneko J, Kishi Y, Akamatsu N, Matsui $Y$, et al. Short hepatic vein reconstruction in biliary atresia patients with absent inferior vena cava. Clin Transplant. 2007;21(1):13-7. 